\title{
Estimativa de produção e valor nutritivo do feno de estilosantes cv. Campo Grande ${ }^{1}$
}

\section{Estimate of production and nutritional value of Stylosanthes hay cv. Campo Grande ${ }^{1}$}

\author{
Mábio Silvan José da Silva ${ }^{2}$; Clóves Cabreira Jobim³; \\ Willian Gonçalves do Nascimento ${ }^{4}$; Geane Dias Gonçalves Ferreira'; \\ Michele Simili da Silva ${ }^{2}$; Tamara Tais Três ${ }^{2}$
}

\section{Resumo}

Objetivou-se com este estudo avaliar a produtividade do estilosantes Campo Grande (ECG), observando a razão folha: caule, bem como o seu potencial para a confecção de feno, de forma a determinar o teor mais adequado de umidade para o enfardamento, o qual proporcionasse as menores perdas na qualidade do feno. $\mathrm{O}$ experimento foi conduzido em um hectare de área plantada, dividido em 12 parcelas. Os tratamentos consistiram em três teores de matéria seca (MS): 600, 700 e $800 \mathrm{~g} / \mathrm{kg}$ de MN, no momento do enfardamento, com quatro repetições cada, em um delineamento inteiramente casualizado. Os dados foram analisados pelo software SAS. Observou-se produtividade média de 3,36 toneladas de matéria natural/hectare. Foi verificado que os fenos se mantiveram estáveis, durante o período de armazenamento (60 dias), exceto para os fenos com teor de MS igual a $600 \mathrm{~g} / \mathrm{kg}$ de MN, que apresentaram elevação de temperatura, superior a ambiente, em $10^{\circ} \mathrm{C}$. Nos fenos com as maiores concentrações de MS, obteve-se melhores resultados de composição químico-bromatológica, sendo constatados maiores concentrações $(\mathrm{P}<0,05)$ de proteína bruta $(\mathrm{PB})$ e menores de nitrogênio insolúvel em detergente neutro (NIDN) e nitrogênio insolúvel em detergente ácido (NIDA). Porém, os fenos com $700 \mathrm{~g}$ de $\mathrm{MS} / \mathrm{kg}$ de $\mathrm{MN}$ apresentaram maiores valores $(\mathrm{P}<0,05)$ de nutrientes digestíveis totais e de digestibilidade "in vitro" da matéria seca, 528,52 e 646,34 g/kg de MS, respectivamente.

Palavras-chave: Armazenamento, digestibilidade in vitro, perdas, razão folha: caule

\begin{abstract}
The aim of this study was to evaluate the productivity of Stylosanthes spp. cv Campo Grande (ECG), observing the leaf: stem ratio, as well as its potential for haymaking, so, to determine the most suitable moisture content for baling, which provides the lowest losses in quality hay. The experiment was conducted in one hectare of planted area, divided into 12 plots. The treatments consisted of three levels of dry matter (DM): 600,700 and $800 \mathrm{~g} / \mathrm{kg}$ fresh matter (FM), at the time of baling, with four repetitions each, in completely randomized experimental design. The data was analyzed by software SAS. There was average productivity of 3.36 tons of fresh matter/ha. It was found that the hay remained stable during the storage period (60 days), except for baled hay with DM content equal to $600 \mathrm{~g} / \mathrm{kg} \mathrm{FM}$, which showed an increase in temperature, above ambient, $10^{\circ} \mathrm{C}$. In baled hay with higher concentrations

1 Parte da dissertação de mestrado do primeiro autor.

2 Discente(s) de Doutorado do Programa de Pós-Graduação em Zootecnia, Universidade Estadual de Maringá, UEM, Maringá, PR.E-mail: mabiosilvan@zootecnista.com.br; micele7@yahoo.com.br; tamaratais@zootecnista.com.br

3 Prof. do Dept ${ }^{\circ}$ de Zootecnia, UEM, Maringá, PR. E-mail: ccjobim@uem.br

4 Profs. do Curso de Zootecnia. Universidade Federal Rural de Pernambuco/Unidade Acadêmica de Garanhuns, UFRPE-UAG, Garanhuns, PE.E-mail: willian@uag.ufrpe.br; geane@uag.ufrpe.br

* Autor para correspondência
\end{abstract}


of MS, it was obtained better results in composition, with highest concentrations found $(\mathrm{P}<0.05)$ of crude protein $(\mathrm{CP})$ and lowest neutral detergent insoluble nitrogen (NDIN) and acid detergent insoluble nitrogen (ADIN). However, the hays with $700 \mathrm{~g} \mathrm{DM} / \mathrm{kg}$ FM, showed higher values $(\mathrm{P}<0.05)$ of total digestible nutrients (TDN) and "in vitro" dry matter digestibility (IVDMD), 528.52 and $646.34 \mathrm{~kg} / \mathrm{kg}$ DM, respectively.

Key words: Storage, in vitro digestibility, losses, leaf: stem ratio

\section{Introdução}

A fenação, segundo Savoie, Caron e Tremblay (2011), é definida como o processo de conversão de uma forragem de alta umidade em produto estável de baixa umidade. Este processo consiste de várias operações mecânicas, incluindo o corte, condicionamento, enleiramento e enfardamento. Em seguida, o feno pode ser armazenado, mantendo-se estável quando o conteúdo de umidade é relativamente baixo.

Apesar do feno ser recomendado para alimentar qualquer categoria animal, em qualquer sistema de criação, isso não é o que se observa de fato, nas condições do Brasil, onde, apenas em algumas propriedades, que dispõem de maior uso de tecnologias, o feno é produzido e/ou adotado como volumoso na dieta dos animais (EVANGELISTA; REIS; MORAIS, 2011).

As leguminosas têm sido utilizadas como pastagens e na produção de feno durante muito tempo, no entanto, nas duas últimas décadas, a adoção da tecnologia da ensilagem tem alcançado grande destaque, principalmente entre os pequenos e médios produtores (ALBRECHT; BEAUCHEMIN, 2003). Isso se deve, em parte, as grandes perdas que ocorrem durante o período de desidratação da forragem para produção de feno, principalmente em condições climáticas adversas, onde o revolvimento da leira é necessário, para acelerar a taxa de desidratação, o que, nas leguminosas, pode provocar perdas mecânicas acentuadas, reduzindo tanto a produção quanto a qualidade. Segundo Bernardes e Reis (2004) o uso de ancinhos, para promover a inversão das leiras, não é aconselhável em leguminosas, porém, são benéficos, após chuvas, ou se as condições de secagem forem inadequadas.
O uso de feno de leguminosas ainda é restrito a cultura da alfafa, o qual abrange o pequeno nicho de mercado dos seletos animais de elite (animais de reprodução, animais de competição ou animais PET). No entanto, com a crescente divulgação das qualidades do estilosantes Campo Grande (ECG), alguns estudos foram desenvolvidos, para avaliar o potencial de utilização desta leguminosa tropical, na forma de feno, para a alimentação animal (SILVA; PEREIRA; LIMA, 2009; SILVA, 2010).

Diante do exposto acima, objetivou-se determinar a produtividade, a relação folha: caule e o valor nutritivo do feno de ECG preparado com diferentes teores de umidade, bem como, avaliar a ocorrência de perdas qualitativas durante o período de armazenamento.

\section{Material e Métodos}

O experimento foi desenvolvido na Fazenda Experimental de Iguatemi - FEI, e no Laboratório de Análise de Alimentos e Nutrição Animal - LANA, pertencentes à Universidade Estadual de Maringá UEM, no estado do Paraná, Brasil. Localizada numa latitude de $23^{\circ} 25^{\prime} \mathrm{S} ; 51^{\circ} 57^{\prime} \mathrm{O}$ e a 550 metros de altitude, a região apresenta clima subtropical (Cfa), segundo a classificação de Köppen, apresentando temperatura média, no mês mais frio, inferior a $18^{\circ} \mathrm{C}$ (mesotérmico) e temperatura média no mês mais quente, acima de $22^{\circ} \mathrm{C}$, com verões quentes, geadas pouco frequentes e tendência de concentração das chuvas nos meses de verão (Tabela 1 ), contudo sem estação seca definida (IAPAR, 2011). O solo da região experimental é classificado do tipo, latossolo vermelho eutroférrico de textura areno-argilosa (GOMES et al., 2011). 
Tabela 1. Valores médios de temperatura, umidade e precipitação pluviométrica da Fazenda Experimental de Iguatemi (FEI) entre os meses de outubro de 2009 a agosto de 2011.

\begin{tabular}{cccccc}
\hline \multirow{2}{*}{ Mês/ano } & \multicolumn{2}{c}{ Temperatura $\left({ }^{\circ} \mathrm{C}\right)$} & \multicolumn{2}{c}{ Umidade $(\%)$} & \multirow{2}{*}{ Precipitação pluviométrica $(\mathrm{mm})$} \\
\cline { 2 - 4 } out/09 & 27,4 & 17,4 & 82,4 & 60,3 & 345,3 \\
nov/09 & 30,6 & 21,2 & 86,8 & 64,5 & 160,2 \\
dez/09 & 28,7 & 20,5 & 89,7 & 77,2 & 274,5 \\
jan/10 & 28,4 & 20,8 & 91,6 & 74,6 & 251,0 \\
fev/10 & 30,7 & 21,5 & 88,3 & 67,6 & 147,4 \\
mar/10 & 29,6 & 20,3 & 82,6 & 62,0 & 174,4 \\
abr/10 & 27,8 & 18,1 & 84,3 & 61,6 & 68,1 \\
mai/10 & 22,9 & 13,6 & 87,7 & 70,0 & 60,8 \\
jun/10 & 24,0 & 12,8 & 77,4 & 60,4 & 15,1 \\
jul/10 & 24,5 & 13,7 & 80,8 & 53,7 & 52,3 \\
ago/10 & 26,5 & 14,1 & 66,4 & 43,6 & 18,0 \\
set/10 & 28,0 & 16,6 & 74,6 & 48,2 & 138,9 \\
out/10 & 27,2 & 16,2 & 84,7 & 54,1 & 208,6 \\
nov/10 & 28,9 & 17,1 & 80,6 & 48,8 & 96,0 \\
dez/10 & 28,0 & 19,2 & 90,4 & 73,8 & 192,2 \\
jan/11 & 29,7 & 20,4 & 92,0 & 69,1 & 189,7 \\
fev/11 & 29,9 & 20,3 & 95,0 & 70,0 & 260,2 \\
mar/11 & 28,1 & 19,3 & 86,1 & 66,0 & 129,5 \\
abr/11 & 27,4 & 17,8 & 88,2 & 65,6 & 111,1 \\
mai/11 & 25,1 & 13,7 & 80,4 & 62,7 & 7,5 \\
jun/11 & 22,3 & 10,4 & 85,7 & 61,9 & 136,8 \\
jul/11 & 23,6 & 14,1 & 81,7 & 61,2 & 137,8 \\
ago/11 & 25,5 & 14,2 & 77,6 & 53,8 & 33,8 \\
\hline
\end{tabular}

Fonte: Adaptado do Laboratório de Análises de Sementes - FEI/UEM (2011).

O ECG foi implantado em um hectare, durante o mês de outubro de 2009, no período da primavera, o qual atende melhor as exigências climáticas da cultura nesta fase. Antes do cultivo da área, realizou-se a análise do solo (Tabelas 2 e 3), sendo realizadas a correção e adubações necessárias, por meio da aplicação de 2 (duas) toneladas de calcário dolomítico (método de saturação por base, para obter saturação de $30 \%$ ), $35 \mathrm{~kg}$ de $\mathrm{P}_{2} \mathrm{O}_{5}$ na forma de superfosfato simples e $60 \mathrm{~kg}$ de $\mathrm{K}_{2} \mathrm{O}$ tendo como fonte cloreto de potássio. A implantação do ECG se deu por semeadura a lanço com uso de distribuidor Vicon, com uma densidade de 4 (quatro) $\mathrm{kg}$ de sementes/ha e incorporado no solo com uso de rolo compactador.

Tabela 2. Análise do solo utilizado no experimento.

\begin{tabular}{|c|c|c|c|c|c|c|c|c|c|c|}
\hline \multicolumn{2}{|c|}{$\mathrm{pH}$} & $\mathrm{Al}^{3+}$ & $\mathrm{H}^{+}+\mathrm{Al}^{3+}$ & $\mathrm{Ca}^{2+}$ & $\mathrm{Mg}^{2+}$ & $\mathrm{K}^{+}$ & SB & CTC & V & $\mathrm{m}$ \\
\hline $\mathrm{CaCl}_{2}$ & $\mathrm{H}_{2} \mathrm{O}$ & & & $\cdots$ & $\mathrm{Cmol}_{\mathrm{c}} \mathrm{d}$ & & & & & $\ldots . .$. \\
\hline 4,1 & 4,8 & 2,1 & 7,13 & 0,22 & 0,17 & 0,07 & 0,46 & 7,59 & 6,06 & 82,03 \\
\hline
\end{tabular}

Fonte: Elaboração dos autores. 
Tabela 3. Análise dos micronutrientes, fósforo (P) e carbono (C) presentes no solo utilizado no experimento.

\begin{tabular}{|c|c|c|c|c|c|}
\hline $\mathrm{Fe}$ & $\mathrm{Zn}$ & $\mathrm{Cu}$ & $\mathrm{Mn}$ & $\mathrm{P}$ & $\mathrm{C}$ \\
\hline & $\ldots \ldots . .$. & & & $\mathrm{mg} \mathrm{dm}^{-3}$ & $\mathrm{~g} \mathrm{dm}^{-3}$ \\
\hline 151,74 & 0,6 & 1,83 & 4,43 & 3,6 & 11,89 \\
\hline
\end{tabular}

Fonte: Elaboração dos autores.

O experimento consistiu na avaliação de três teores de umidade na massa da forragem de ECG no momento do enfardamento $(600,700$ e $800 \mathrm{~g}$ de $\mathrm{MS} / \mathrm{kg}$ de $\mathrm{MN}$ ), com quatro repetições, sendo os tratamentos distribuídos aleatoriamente em 12 parcelas, de $830 \mathrm{~m}^{2}$ cada. Foram avaliados 10 fardos de feno por parcela, totalizando 40 fardos por tratamento. Avaliou-se ainda a produção de massa de forragem, a composição química e a razão folha: caule.

Após cerca de 100 dias, quando o ECG se apresentava com altura aproximada de $40 \mathrm{~cm}$, iniciou-se as seguintes mensurações e as avaliações:

Produção de massa - A produção de massa de forragem ( $\mathrm{t} / \mathrm{ha}$ ), antes do corte para confecção do feno, foi estimada quando a cultura apresentava entre 35 e $40 \mathrm{~cm}$ de altura, sendo obtida por meio de amostragem destrutiva, com cortes de 12 quadrados de $0,25 \mathrm{~m}^{2}$ em cada parcela.

Perdas qualitativas no material fenado-Após a mensuração da produção de massa, todo o ECG da área experimental foi cortado e deixado sobexposição solar, onde, em intervalos regulares de tempo, eram feitas amostragens para acompanhamento do processo de desidratação, por meio da análise de MS pela metodologia de micro-ondas, descrita por Silva e Queiroz (2002), e determinação do momento certo do enfardamento. Depois de enfardados, o feno foi armazenado em galpão próprio na FEI. As medidas de perdas qualitativas, durante o processo de produção do feno, foram estimadas tendo como referência a composição químico-bromatológica relativa a matéria seca (MS), proteína bruta (PB), matéria mineral (MM), fibra em detergente neutro (FDN), fibra em detergente ácido (FDA), nitrogênio insolúvel em detergente neutro (NIDN), nitrogênio insolúvel em detergente ácido (NIDA), digestibilidade "in vitro" da matéria seca (DIVMS), nutrientes digestíveis totais (NDT) e carboidratos não estruturais (CNE) da forragem no momento do corte comparada com a composição do feno após 60 dias de armazenagem.

\section{Medidas de temperatura e de umidade no} interior dos fardos - Foram realizadas medidas de temperatura no interior dos fardos no momento do enfardamento e aos 2, 4 e 6 dias após, utilizandose termômetro digital (modelo GULTERM 1001). Também foram registradas a temperatura ambiente e umidade relativa do ar, dados obtidos na estação meteorológica da UEM.

Composição químico-bromatológica do feno e digestibilidade da MS - Cerca de 60 dias após o enfardamento, as amostras dos fenos foram présecas em estufa de circulação forçada de ar por $72 \mathrm{~h}$ a $55^{\circ} \mathrm{C}$, e moídas em peneira de $1,0 \mathrm{~mm}$ de crivo, em moinho de faca tipo Willey, e levadas ao laboratório, onde foram determinados os teores de MS, PB, extrato etéreo (EE) e matéria orgânica (MO), segundo métodos descritos por Silva e Queiroz (2002). A determinação de FDN e FDA, NIDA, NIDN e lignina (LIG) foram obtidos de acordo com Van Soest, Robertson e Lewis (1991). Os valores de PIDA e PIDN foram obtidos pela multiplicação dos valores de NIDA e NIDN por 6,25 . Os valores de carboidratos totais (CHT) foram calculados pela equação $\mathrm{CHT}=\mathrm{MO}-(\mathrm{EE}+\mathrm{PB})$ e os nutrientes digestíveis totais (NDT), segundo as equações do NRC (2001), NDT $=\{0,98 \times(100$ $-[($ FDN $-\mathrm{NIDN})+\mathrm{PB}+\mathrm{EE}+\mathrm{MM}])\}+\{\mathrm{PB} \times$ $\left.\exp ^{[-1,2 \times(\mathrm{NIDA} / \mathrm{PB})}\right\}+\{0,75 \times[(\mathrm{NIDN}-\mathrm{FDN})-\mathrm{LIG}]$ $\left.\mathrm{x}\left[1-(\mathrm{LIG} /(\mathrm{NIDN}-\mathrm{FDN}))^{0,667}\right]\right\}+$ DEE, sendo 
$\mathrm{DEE}=\% \mathrm{EE}$, porém, quando a $\% \mathrm{EE}<1, \mathrm{DEE}=0$. Determinaram-se ainda as frações dos carboidratos, sendo que a fração $\mathrm{C}$ foi determinada pela fórmula descrita por Sniffen et al. (1992), C = (100 x FDN (\%MS) x 0,01 x LIG (\%FDN) x 2,4/CHT (\%MS)); a fração $B_{2}$ foi obtida pela equação $B_{2}=100 x$ $((\mathrm{FDN}(\% \mathrm{MS})-\mathrm{PIDN}(\% \mathrm{~PB}) \times 0,01 \times \mathrm{PB}(\% \mathrm{MS}))$ - FDN (\%MS) x 0,01 x LIG (\%FDN) x 2,4)))/ $\mathrm{CHT}(\% \mathrm{MS})$ e a fração $\mathrm{A}+\mathrm{B}_{1}$ foi determinada pela diferença entre $100-\left(\mathrm{C}+\mathrm{B}_{2}\right)$.

A digestibilidade "in vitro" da MS (DIVMS) foi obtida segundo a metodologia descrita por Tilley e Terry (1963), seguindo as modificações descritas por Holden (1999), com uso do equipamento Daisy II (ANKOM technology).

O delineamento experimental utilizado foi o inteiramente casualizado, e os dados obtidos foram submetidos à análise de variância e análise de regressão utilizando o programa estatístico SAS (2009). As diferenças entre as médias foram analisadas pelo teste Tukey $(\mathrm{P}<0,05)$, utilizando-se do seguinte modelo estatístico:

Yij $=\mu+T_{i}+\varepsilon_{i j}$,em que:

$\mathrm{Y}_{\mathrm{ij}}=$ valores observados para os diferentes tratamentos; $\mu=$ constante referente a todas as observações; $\mathrm{T}_{\mathrm{i}}=$ efeito do i-ésimo tratamento, onde $\mathrm{i}=1$ a $3 ; \varepsilon_{\mathrm{ij}}=$ erro aleatório associado a cada observação.

\section{Resultados e Discussão}

Produção e qualidade do estilosantes cv. Campo Grande

A produção estimada de massa de forragem do estilosantes, antes do corte para o enfardamento foi de 3,36 toneladas/ha de matéria natural, equivalendo a $1,09 \mathrm{t} / \mathrm{ha} /$ corte de matéria seca. $\mathrm{O}$ período entre a implantação da cultura e o corte foi de aproximadamente 100 dias, tempo necessário para o estilosantes atingir a altura entre 35 e $40 \mathrm{~cm}$. Produtividade superior a obtida nesse estudo foi constatada por Oliveira Neto et al. (2009), que observaram valores de 1,3 e 10,1 t/ha aos 40 e aos 90 dias de rebrota, respectivamente. Fato este, que pode ser atribuído à presença, em algumas áreas, de plantas invasoras, ocasionando competitividade e menor desempenho produtivo do ECG. A produtividade média do ECG, em sistema de monocultivo, é de 8 a 14 toneladas/ha/ano de matéria seca e de 3 a $6 \mathrm{t} / \mathrm{ha} / \mathrm{ano}$, quando consorciada com gramíneas, assumindo-se que a participação da leguminosa na pastagens é de 30\% a 40\% da matéria seca de forragem produzida (EMBRAPA, 2007).

Do total de massa produzida, observou-se uma média de produção de $373,24 \mathrm{~g} / \mathrm{kg}$ de MS de folhas e $626,76 \mathrm{~g} / \mathrm{kg}$ de MS de caule, conferindo uma razão folha: caule de 0,6 . Valores superiores foram encontrados por Teixeira et al. (2010), em $S$. guianensis cv. Bandeirantes, S. guianensis cv. Cook, $S$. guianensis cv. Mineirão e S. macrocephala cv. Pioneiro, os quais apresentaram valores de relação folha: colmo de 0,$8 ; 0,7 ; 0,8$ e 0,9 , respectivamente, sendo que eles foram cortados rente ao solo aos 102 dias após o plantio. Valores semelhantes aos relatados por Teixeira et al. (2010), foram observados por Moura et al. (2011) trabalhando com estilosantes Campo Grande submetidos a cinco idades de corte $(30,35,40,45$ e 50 dias $)$ e tratado com e sem adubação fosfatada.

Conhecer a razão folha: caule existente em uma planta forrageira é de suma importância, visto que, esta variável interfere no consumo de forragem por parte dos animais, que apresentam o hábito de selecionar a porção mais tenra e de melhor valor nutricional (folhas). O conhecimento da razão F:C, além das inferências de qualidade da massa de forragem, permitem avaliar alguns parâmetros fisiológicos das plantas, pois, de acordo com Taiz e Zeiger (2004), as plantas que apresentam maiores quantidades de folhas, apresentam maior capacidade de realizar fotossíntese, bem como, maior potencial de fixação de nitrogênio $(\mathrm{N})$, já que o maior teor de $\mathrm{N}$ se encontra nas folhas, como constituinte da clorofila e da enzima Ribulose bifosfato carboxilase- 
oxigenase (Rubisco). Segundo Wedin (2004), citado por Teixeira et al. (2010), em uma típica planta $\mathrm{C}_{3}$, de 20 a $30 \%$ do $\mathrm{N}$ encontrado nas folhas fazem parte da Rubisco.
Os valores de composição químicobromatológica do ECG, bem como das suas frações constituintes (folhas e caule) estão apresentados na Tabela 4.

Tabela 4. Composição químico-bromatológica ( $\mathrm{g} / \mathrm{kg}$ de MS) e digestibilidade "in vitro" da matéria seca (DIVMS) das diferentes frações do Stylosanthes spp. cv. Campo Grande.

\begin{tabular}{cccccc}
\hline Item & Planta Inteira & Folhas & Caule & Média & *CV (\%) \\
\hline MS $^{1}$ & $267,23^{\mathrm{a}}$ & $227,64^{\mathrm{b}}$ & $235,49^{\mathrm{b}}$ & 243,45 & 6,71 \\
MM & $53,62^{\mathrm{ab}}$ & $64,60^{\mathrm{a}}$ & $50,29^{\mathrm{b}}$ & 56,17 & 11,25 \\
EE & $13,11^{\mathrm{b}}$ & $14,73^{\mathrm{a}}$ & $5,75^{\mathrm{c}}$ & 11,20 & 7,06 \\
PB & $118,84^{\mathrm{b}}$ & $222,66^{\mathrm{a}}$ & $96,19^{\mathrm{c}}$ & 145,90 & 7,20 \\
NIDN & $7,31^{\mathrm{b}}$ & $20,15^{\mathrm{a}}$ & $6,73^{\mathrm{b}}$ & 11,40 & 11,82 \\
NIDA & $2,83^{\mathrm{a}}$ & $1,54^{\mathrm{c}}$ & $2,19^{\mathrm{b}}$ & 2,18 & 10,12 \\
FDN & $653,32^{\mathrm{a}}$ & $530,09^{\mathrm{b}}$ & $684,18^{\mathrm{a}}$ & 622,53 & 7,85 \\
FDA & $503,16^{\mathrm{a}}$ & $295,55^{\mathrm{b}}$ & $529,19^{\mathrm{a}}$ & 442,63 & 6,56 \\
LIG & $160,72^{\mathrm{a}}$ & $80,82^{\mathrm{b}}$ & $149,62^{\mathrm{a}}$ & 130,39 & 5,93 \\
CHT & $814,43^{\mathrm{b}}$ & $698,01^{\mathrm{c}}$ & $847,77^{\mathrm{a}}$ & 786,74 & 1,88 \\
NDT & $458,95^{\mathrm{b}}$ & $622,59^{\mathrm{a}}$ & $442,25^{\mathrm{b}}$ & 507,93 & 19,61 \\
DIVMS & $526,12^{\mathrm{b}}$ & $735,39^{\mathrm{a}}$ & $540,88^{\mathrm{b}}$ & 600,79 & 5,44 \\
\hline
\end{tabular}

Médias na mesma linha, seguidas de letras diferentes, diferem entre si pelo teste Tukey $(\mathrm{P}<0,05)$. ${ }^{1} \mathrm{MS}=$ matéria seca $(\mathrm{g} / \mathrm{kg}$ de $\mathrm{MN}) ; \mathrm{MM}=$ matéria mineral; $\mathrm{EE}=$ extrato etéreo; $\mathrm{PB}=$ proteína bruta; $\mathrm{NIDN}=$ nitrogênio insolúvel em detergente neutro; NIDA = nitrogênio insolúvel em detergente ácido; LIG = lignina; $\mathrm{CHT}=$ carboidratos totais; $\mathrm{NDT}=$ nutrientes digestíveis totais; $* \mathrm{CV}=$ coeficiente de variação.

Fonte: Elaboração dos autores.

Verificou-se que houve diferença $(\mathrm{P}<0,05)$ entre os teores de MS presente na planta inteira, em relação às folhas e caule, os quais apresentaram menores concentrações. Oliveira Neto et al. (2009), encontraram valores superiores em ECG cortados aos 90 dias $(298,20 \mathrm{~g} / \mathrm{kg}$ de MS), tendo observado que as concentrações da MS aumentaram com o tempo de corte. De acordo com Taiz e Zeiger (2004), com o aumento da idade das plantas ocorre aumento nas concentrações de MS, reduzindo em proporção, as concentrações dos constituintes não estruturais, consequentemente, reduzindo a qualidade nutricional dos tecidos das plantas.

Quanto aos teores de MM, observou-se valor médio de $56,17 \mathrm{~g} / \mathrm{kg}$. Entretanto, verificou-se que não houve diferença significativa $(\mathrm{P}>0,05)$ entre as frações folhas $(64,60 \mathrm{~g} / \mathrm{kg}$ de MS) e caule $(50,29 \mathrm{~g} /$ $\mathrm{kg}$ de MS), respectivamente. Teixeira et al. (2010) relataram valores superiores das frações folhas e colmos em S. guianensis cv. Bandeirantes (115 e 82 g/kg de MS), S. guianensis cv. Cook (114 e 106 g/ $\mathrm{kg}$ de MS), S. guianensis cv. Mineirão (107 e 87 g/ $\mathrm{kg}$ de MS) e $S$. macrocephala cv. Pioneiro (122 e 83 $\mathrm{g} / \mathrm{kg}$ de MS), respectivamente.

As concentrações de minerais variam consideravelmente entre as partes das plantas, tanto sazonalmente como em função do estágio de maturidade. Porém, as concentrações de nutrientes são, geralmente, maiores nos tecidos jovens, quando comparados aos tecidos mais velhos, embora o padrão de mudança com a idade possa incorrer em erros, em se tratando de micronutrientes (GIBSON, 2009).

As concentrações de EE diferiram $(\mathrm{P}<0,05)$ entre a planta inteira e suas frações constituintes, sendo os maiores valores encontrados nas folhas $(14,73 \mathrm{~g} / \mathrm{kg}$ de MS) e o menor no caule $(5,75 \mathrm{~g} /$ 
$\mathrm{kg}$ de MS). Este comportamento ocorre devido a maior concentração de lipídeos constituintes da clorofila, plastoquinonas, carotenóides e tocoferóis, que juntos correspondem a um terço dos lipídios das folhas dos vegetais. Além disso, nas folhas das plantas se encontram as ceras, que constituem a cutícula protetora, atuante na redução das perdas de água (TAIZ; ZEIGER, 2004). Apesar das plantas apresentarem lipídios estruturais em suas membranas, tais como os esfingolipídios e esteróis, estes são componentes minoritários (GIBSON, 2009). Os maiores valores de $P B$ foram observados nas folhas $(\mathrm{P}<0,05)$, que apresentaram $222,66 \mathrm{~g} / \mathrm{kg}$ de MS, corroborando com o relatado pela Embrapa (2007), que foi de $220 \mathrm{~g} / \mathrm{kg}$ de MS. No entanto, os teores de PB observados na planta inteira foram de $118,84 \mathrm{~g} / \mathrm{kg}$ de MS, apresentando-se inferior ao obtido por Oliveira Neto et al. (2009), de 133,90 g/ $\mathrm{kg}$ de MS, em ECG cortado aos 90 dias. Segundo a Embrapa (2007), geralmente as concentrações de PB, na planta inteira, situa-se entre 130 a 180 $\mathrm{g} / \mathrm{kg}$ de MS, durante a estação chuvosa. Porém, durante a estação seca, ocorre redução nos teores de PB das plantas devido a perda de folhas, de modo que o ECG pode chegar a uma produção de $60 \mathrm{~g} /$ $\mathrm{kg}$ de MS, nas condições do Mato Grosso do Sul (BARCELLOS et al., 2001).

Do mesmo modo que a PB, as folhas apresentaram as concentrações mais altas de NIDN. Em contrapartida, os teores de NIDA foram menores $(\mathrm{P}<0,05)$, demonstrando uma boa disponibilidade do nitrogênio para a microbiota ruminal. A análise dos teores de NIDA no alimento é de grande importância, pois representa a fração do N-total indisponível ao animal, uma vez que é oriunda da complexação de compostos protéicos com a FDA. Desta forma, quanto menor for a relação NIDA/N-total, maior será a quantidade de $\mathrm{N}$ e, consequentemente, de $\mathrm{PB}$ disponível ao metabolismo animal, melhorando a sua digestibilidade.
A fração folha apresentou menores valores de FDN, FDA e lignina $(\mathrm{P}<0,05)$ em relação a fração caule. Oliveira Neto et al. (2009) observaram resultado superior de FDN, em ECG cortados aos 90 dias (591 g/kg de MS), em relação as plantas deste experimento, na qual se obteve FDN de $653,32 \mathrm{~g} / \mathrm{kg}$ de MS. Os teores de FDN presente na fração folha foram de 530,09 $\mathrm{g} / \mathrm{kg}$ de MS. Tal quantidade pode caracterizar como fator limitante ao consumo do ECG pelos animais, uma vez que, segundo Mertens (1992), a proporção de FDN está relacionada com o consumo máximo de matéria seca, onde, plantas que apresentam elevados teores, geralmente superiores a $500 \mathrm{~g} / \mathrm{kg}$ de MS, limitam a ingestão de alimentos e consequentemente o consumo de energia. Porém, Van Soest (1994), relataram que valores superiores a $550 \mathrm{~g} / \mathrm{kg}$ de FDN na matéria seca, correlaciona-se negativamente com o consumo de forragens.

A concentração de FDA observada nas folhas foi de 295,55 g/kg de MS, enquanto que na planta inteira foi de 503,16 g/ $\mathrm{kg}$ de MS. Tais valores, associados aos da FDN, tendem a conferir ao ECG um baixo consumo e digestibilidade reduzida, pois, segundo Nussio, Manzano e Pedreira (1998), as forrageiras que apresentam valores de FDA próximos ou superiores a $400 \mathrm{~g} / \mathrm{kg}$ de MS são pouco consumidas e apresentam baixa digestibilidade.

Quanto às frações constituintes dos carboidratos totais (CHT), observou-se alta proporção da fração $\mathrm{C}$ nas plantas e no caule $(\mathrm{P}<0,05)$, em relação às folhas (Tabela 5). A fração $\mathrm{C}$ constitui a porção da parede celular que não é digerida ao longo de sua permanência no trato gastrointestinal, sendo menos observada nas folhas e tecidos jovens das plantas (SNIFFEN et al., 1992). Desta forma, os tecidos mais velhos tendem a apresentar menores concentrações das frações $A+B_{1}$ e $B_{2}$. 
Tabela 5. Frações de carboidratos (g/kg de CHT) nas diferentes frações do Stylosanthes spp. cv. Campo Grande.

\begin{tabular}{lcccc}
\hline \multirow{2}{*}{ Frações da planta } & \multicolumn{4}{c}{ Frações do CHT } \\
\cline { 2 - 5 } & $\mathrm{CHT}$ & $\mathrm{A}+\mathrm{B}_{1}$ & \multicolumn{1}{c}{$\mathrm{B}_{2}$} & $\mathrm{C}$ \\
\hline Planta Inteira & $814,43^{\mathrm{b}}$ & $254,35^{\mathrm{b}}$ & $295,21^{\mathrm{a}}$ & $450,44^{\mathrm{a}}$ \\
Folhas & $698,01^{\mathrm{c}}$ & $421,64^{\mathrm{a}}$ & $329,84^{\mathrm{a}}$ & $248,52^{\mathrm{b}}$ \\
Caule & $847,77^{\mathrm{a}}$ & $242,47^{\mathrm{b}}$ & $345,65^{\mathrm{a}}$ & $411,88^{\mathrm{a}}$ \\
\hline Média & 786,74 & 306,15 & 323,56 & 370,28 \\
CV $(\%)$ & 1,88 & 21,08 & 12,66 & 8,93 \\
\hline
\end{tabular}

Médias na mesma coluna, seguidas de letras diferentes, diferem entre si pelo teste Tukey $(\mathrm{P}<0,05)$.

Fonte: Elaboração dos autores.

Malafaia et al. (1998), trabalhando com a soja perene, registraram menores concentrações, em relação ao ECG, de CHT e da fração C (744 e 368 $\mathrm{g} / \mathrm{kg}$ de $\mathrm{MS}$, respectivamente) e maiores valores das frações $\mathrm{A}+\mathrm{B}_{1}$ e $\mathrm{B}_{2}(293$ e $339 \mathrm{~g} / \mathrm{kg}$ de $\mathrm{MS}$, respectivamente).

Apesar dos teores observados de FDN e FDA ultrapassarem os valores limites de 500 e $400 \mathrm{~g} / \mathrm{kg}$ de MS, respectivamente, os quais permitem uma adequada taxa de consumo e digestibilidade da planta forrageira, observou-se valor médio de NDT de $507,93 \mathrm{~g} / \mathrm{kg}$ de MS e um coeficiente médio de digestibilidade in vitro da matéria seca de $600 \mathrm{~g} / \mathrm{kg}$ de MS (Tabela 4), o que se deve, em parte, à maior contribuição das frações $A+B_{1}$ e $B_{2}$, constituintes dos CHT presentes nas folhas (Tabela 5). Associado a isso, tem-se as reduzidas concentrações de NIDN e NIDA, que refletem a melhor qualidade da forragem, pois quanto menor for a NIDN e NIDA, principalmente a NIDA, maior será a disponibilidade de $\mathrm{N}$, e consequentemente de $\mathrm{PB}$, melhorando assim a digestibilidade. Tal fato foi comprovado, nesse experimento, pelo alto coeficiente de correlação positiva entre a concentração de PB e a DIVMS, que foi de 0,926 .

Os dados de DIVMS, apresentados na Tabela 4, corroboram com os descritos pela Embrapa (2007), cujos valores de digestibilidade in vitro da matéria orgânica estão entre 550 e 700 g/kg de MS.
Verificou-se forte correlação entre os teores de FDN, FDA, NIDA, lignina e a fração C com o conteúdo de MS, sendo encontrados os valores de 0,$507 ; 0,507 ; 0,795 ; 0,630$ e 0,717 , respectivamente. Assim, evidenciando que quanto mais jovem for a planta forrageira, menor o conteúdo destes, caracterizando assim, uma planta tenra, com maior consumo pelos animais e maiores coeficientes de digestibilidade. Verificou-se correlação negativa entre conteúdo de FDN, FDA, NIDA, lignina e da fração C, com a DIVMS. Fato esse, que pode determinar limitação do consumo devido a FDN e pela composição da FDA, a qual é composta, segundo Silva e Queiroz (2002), de celulose e lignina, que comprometem a digestibilidade da forragem devido a ligação de alguns nutrientes a fibra, em especial a lignina, tornando-se indisponível ou pouco disponível aos animais.

Qualidade do feno de estilosantes cv. Campo Grande

A composição químico-bromatológica dos fenos de estilosantes Campo Grande, enfardados com diferentes teores de matéria seca (MS), encontra-se na Tabela 6. 
Tabela 6. Composição químico-bromatológica ( $\mathrm{g} / \mathrm{kg}$ de MS) e digestibilidade "in vitro" da matéria seca (DIVMS) dos fenos de Stylosanthes spp. cv. Campo Grande, confeccionados com diferentes teores de matéria seca no momento do enfardamento.

\begin{tabular}{crrrrc}
\hline \multirow{2}{*}{ Item } & \multicolumn{3}{c}{ Tratamentos $(\mathrm{g}$ de MS/kg de MN $)$} & \multirow{2}{*}{ Média } & \multirow{2}{*}{$*$ CV $(\%)$} \\
\cline { 2 - 3 } & \multicolumn{1}{c}{600} & 700 & 800 & & \\
\hline MS $^{1}$ & $503,13^{\mathrm{c}}$ & $579,18^{\mathrm{b}}$ & $727,39^{\mathrm{a}}$ & 603,23 & 0,12 \\
MM & $58,08^{\mathrm{a}}$ & $53,03^{\mathrm{a}}$ & $51,18^{\mathrm{a}}$ & 54,10 & 7,69 \\
EE & $5,95^{\mathrm{b}}$ & $11,42^{\mathrm{a}}$ & $12,32^{\mathrm{a}}$ & 9,90 & 7,62 \\
PB & $113,28^{\mathrm{b}}$ & $119,33^{\mathrm{a}}$ & $124,02^{\mathrm{a}}$ & 118,88 & 2,04 \\
NIDN & $6,20^{\mathrm{a}}$ & $5,47^{\mathrm{b}}$ & $4,90^{\mathrm{c}}$ & 5,52 & 4,32 \\
NIDA & $2,44^{\mathrm{a}}$ & $1,65^{\mathrm{c}}$ & $2,20^{\mathrm{b}}$ & 2,10 & 3,50 \\
FDN & $607,82^{\mathrm{a}}$ & $582,53^{\mathrm{b}}$ & $620,36^{\mathrm{a}}$ & 603,57 & 1,79 \\
FDA & $463,25^{\mathrm{b}}$ & $418,88^{\mathrm{c}}$ & $477,24^{\mathrm{a}}$ & 453,12 & 1,38 \\
LIG & $149,36^{\mathrm{a}}$ & $121,70^{\mathrm{b}}$ & $155,76^{\mathrm{a}}$ & 142,27 & 3,46 \\
CHT & $822,69^{\mathrm{a}}$ & $816,22^{\mathrm{ab}}$ & $812,48^{\mathrm{b}}$ & 817,13 & 0,47 \\
NDT & $460,74^{\mathrm{b}}$ & $528,51^{\mathrm{a}}$ & $476,21^{\mathrm{b}}$ & 488,48 & 7,27 \\
DIVMS & $581,48^{\mathrm{b}}$ & $646,34^{\mathrm{a}}$ & $583,41^{\mathrm{b}}$ & 603,74 & 1,04 \\
\hline
\end{tabular}

Médias na mesma linha, seguidas de letras diferentes, diferem entre si pelo teste Tukey $(\mathrm{P}<0,05) .{ }^{1} \mathrm{Matéria} \mathrm{seca}(\mathrm{g} / \mathrm{kg}$ de $\mathrm{MN})$; $\mathrm{MM}$ = matéria mineral; $\mathrm{EE}=$ extrato etéreo; $\mathrm{PB}=$ proteína bruta; $\mathrm{NIDN}=$ nitrogênio insolúvel em detergente neutro; $\mathrm{NIDA}=$ nitrogênio insolúvel em detergente ácido; LIG = lignina; $\mathrm{CHT}=$ carboidratos totais; NDT $=$ nutrientes digestíveis totais; $* \mathrm{CV}=\mathrm{coeficiente}$ de variação.

Fonte: Elaboração dos autores.

Pode-se observar que os valores de umidade no momento do enfardamento, apresentaram-se variáveis em relação aos previamente estabelecidos, de forma que, os fenos foram enfardados com teores de MS iguais a 555,55; 634,83 e 798,07 $\mathrm{g} / \mathrm{kg}$ de $\mathrm{MN}$ para os tratamentos de 600,700 e $800 \mathrm{~g}$ de $\mathrm{MS} / \mathrm{kg}$ de $\mathrm{MN}$, respectivamente. Desta forma, observouse que os teores de umidade permaneceram menores nos fenos enfardados com maior teor de MS, verificando-se, no entanto, aumento no teor de umidade dos fenos, no momento da avaliação, na ordem de 52,42; 55,65 e 70,68 g/kg de MS em relação ao momento do enfardamento, o que pode ter ocorrido devido o feno ser higroscópico, associado às condições de umidade durante o período de armazenamento, as quais atingiram, em alguns meses valores superiores a 90\% (Tabela 1).

Os teores de MM presente nos fenos, não diferiram $(\mathrm{P}<0,05)$ entre os tratamentos, apresentando valor médio de 54,10 g/ $\mathrm{kg}$ de MS. Valores superiores foram relatados por Silva (2010), que observou concentração de $80 \mathrm{~g}$ de $\mathrm{MM} / \mathrm{kg}$ de MS nos fenos de estilosantes, no entanto, Padua et al. (2006) avaliando o feno de soja perene e kudzu tropical, obtiveram valores de 55,0 e 51,8 g de MM/ $\mathrm{kg}$ de MS, respectivamente.

Nos fenos enfardados com teores de MS de 600 $\mathrm{g} / \mathrm{kg}$ de $\mathrm{MN}$, verificaram-se menores quantidades de EE $(\mathrm{P}<0,05)$, em relação aos tratamentos com 700 e $800 \mathrm{~g}$ de $\mathrm{MS} / \mathrm{kg}$ de $\mathrm{MN}$, porém as concentrações nestes dois últimos não diferiram entre si. As menores concentrações de EE, possivelmente, são resultantes do período respiratório prolongado, pois quanto maior o tempo até ocorrer a paralisação do metabolismo celular, maior será a utilização de compostos energéticos. Além disso, nos tratamentos com maiores teores de MS, ocorre o efeito da concentração de alguns nutrientes, dentre eles o EE.

Observou-se que a composição do feno, quanto a $\mathrm{PB}$, diferiu estatisticamente $(\mathrm{P}<0,05)$, entre o tratamento de menor teor de MS e os demais, tendo apresentado uma concentração protéica de 113,$28 ; 119,33$ e $124,02 \mathrm{~g} / \mathrm{kg}$ de MS, para os tratamentos com MS de 600, 700 e $800 \mathrm{~g} / \mathrm{kg}$ de $\mathrm{MN}$, respectivamente. 
Silva (2010), avaliando feno de ECG, relatou valores de PB igual a $122 \mathrm{~g} / \mathrm{kg}$ de MS em fenos com $899 \mathrm{~g}$ de $\mathrm{MS} / \mathrm{kg}$ de $\mathrm{MN}$, corroborando com os dados encontrados no presente trabalho. Coblentz, Hoffman e Martin (2010), estudando o feno de alfafa com alta umidade, obtiveram valores médios de PB na ordem de $185 \mathrm{~g} / \mathrm{kg}$ de MS.

Segundo as recomendações do NRC (2007), as concentrações de PB encontradas no feno de ECG são suficientes para atender às exigências de éguas no período gestacional, bem como, de equinos desenvolvendo exercícios pesados, os quais apresentam requerimentos de 110 e $120 \mathrm{~g}$ de $\mathrm{PB} / \mathrm{kg}$ de MS na dieta, respectivamente.

Durante a fenação, pode-se ter perdas no valor protéico do feno, devido ao intenso processo de manejo, durante a secagem das leguminosas. De acordo com Reis e Moreira (2011) as forragens devem ser cortadas para fenação contendo valores de umidade entre 700 e $800 \mathrm{~g} / \mathrm{kg}$ de $\mathrm{MN}$, ou seja, quando a forragem apresenta de 2,3 a 5,6 partes de água para cada parte de MS, sendo após, submetidas ao processo de murcha, o qual tende a reduzir o teor de umidade para uma faixa de 120 a $180 \mathrm{~g} / \mathrm{kg}$ de $\mathrm{MN}$, permitindo assim o armazenamento do feno com segurança e baixas perdas. Porém, a ocorrência de uma secagem excessiva é prejudicial à fenação, pois nas leguminosas, favorece o desprendimento muito intenso das folhas, e consequente diminuição da PB (SOARES FILHO, 2011).

A concentração de PB do feno foi fortemente correlacionada com a de MS, demonstrando um comportamento linear, conforme demonstrado na Figura 1. Isso evidencia o aumento, em termos proporcionais, das concentrações de PB devido ao decréscimo nos conteúdos de carboidratos solúveis, já que as concentrações de PB, FDN, FDA e lignina não são diretamente afetadas pela atividade respiratória (REIS; MOREIRA; PEDREIRA, 2001). Verificou-se a existência de correlação inversa entre o NIDN e a MS.

Figura 1. Concentração de PB do feno de Stylosanthes spp. cv. Campo Grande em função de diferentes teores de MS no momento do enfardamento.

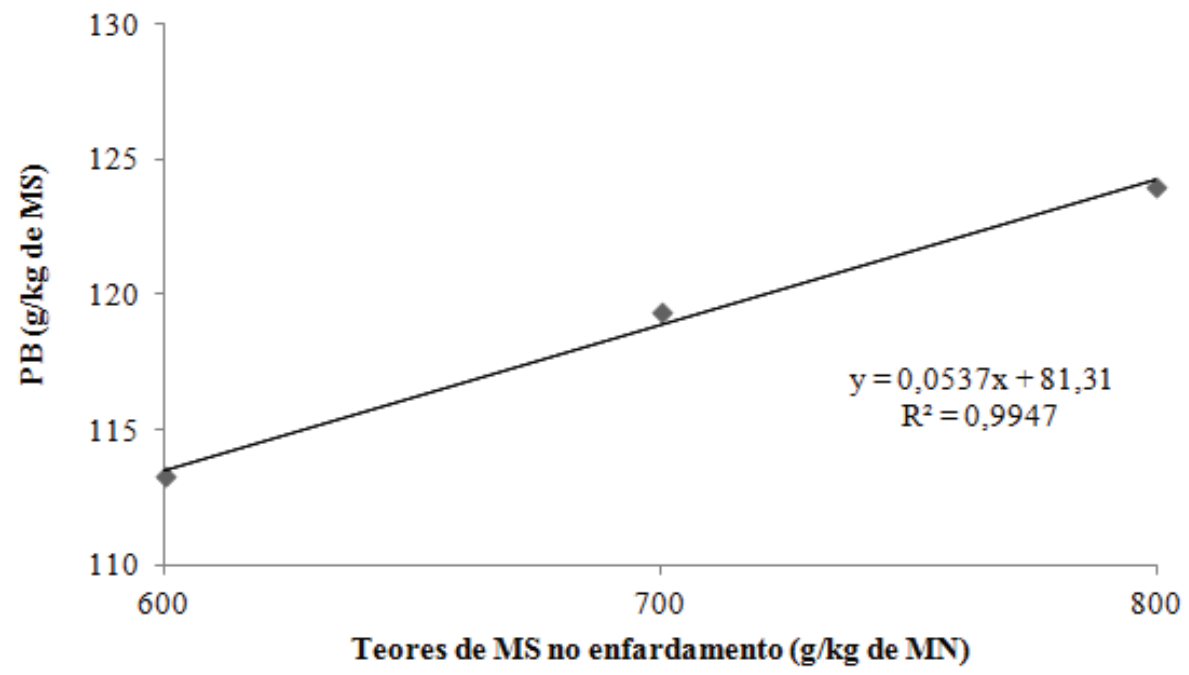

Fonte: Elaboração dos autores. 
Os valores de NIDN e NIDA diferiram entre si $(\mathrm{P}<0,05)$, para todos os tratamentos, sendo os menores resultados (média de 4,90 g/ $\mathrm{kg}$ de MS), para NIDN, presente no feno de maior MS, enquanto, para NIDA, os menores teores (média de $1,65 \mathrm{~g} / \mathrm{kg}$ de MS) foram encontrados no feno com MS intermediária (Tabela 6). Desta forma, o feno com MS igual a $700 \mathrm{~g} / \mathrm{kg}$ apresentou maior disponibilidade de PB para a utilização animal, haja vista que também apresentou as maiores concentrações de PB. Em fenos de alfafa, Coblentz, Hoffman e Martin (2010) encontraram concentrações superiores de NIDN e NIDA, as observada no presente trabalho, sendo os valores, por eles encontrados, de 12 e $3,84 \mathrm{~g} / \mathrm{kg}$ de MS, respectivamente.

Observou-se que os fenos que apresentaram maiores teores de NIDA, foram os mesmos, nos quais houve a maior elevação na temperatura durante o período de armazenamento (Tabela 6 e Figura 3). A presença de nitrogênio indigestível ligado a fração fibrosa (NIDA) é um indicador do possível aquecimento em silagens e fenos, que podem desencadear a reação de Maillard durante a secagem no campo ou armazenamento, promovendo a polimerização da hemicelulose e de açúcares com os grupamentos amino dos aminoácidos (VAN SOEST, 1994; COBLENTZ; HOFFMAN, 2009a).

As concentrações de FDN e FDA diferiram $(\mathrm{P}<0,05)$ entre os tratamentos, com destaque para o feno enfardado com $700 \mathrm{~g}$ de $\mathrm{MS} / \mathrm{kg}$ de $\mathrm{MN}$, que apresentou os menores valores de ambos, 582,53 e 418,88 g/kg de MS, respectivamente. Esse comportamento evidencia menores perdas de outros compostos não estruturais, podendo significar que o processo de desidratação foi mais eficiente nesse tratamento. O comportamento do conteúdo da FDN e da FDA ocorreu de forma semelhante entre os tratamentos.

Valores próximos ao encontrado neste experimento, foram observados por Freitas et al. (2002), em fenos de alfafa, sendo registrado concentrações médias de 581 e $424 \mathrm{~g} / \mathrm{kg}$ de MS para FDN e FDA, respectivamente. Coblentz e Hoffman (2009b) observaram valores médios de FDN, em fenos de alfafa com alta umidade, umidade intermediária e baixa umidade, na ordem de 570, 534 e $439 \mathrm{~g} / \mathrm{kg}$ de MS, respectivamente. Os mesmos autores encontraram, no mesmo material, valores de 397, 346 e $284 \mathrm{~g}$ de FDA/kg de MS.

Em feno de leguminosas tropicais, como a soja perene e o kudzu tropical, Pádua et al. (2006) observaram valores de FDN maiores que o encontrado para o feno de ECG, enfardado com $700 \mathrm{~g}$ de $\mathrm{MS} / \mathrm{kg}$ de $\mathrm{MN}$, de forma que os valores observados foram de 602,9 e 624,7 g de FDN/kg de MS, respectivamente. Concentrações médias de FDA iguais a 405,9 e 394,8 g/ $\mathrm{kg}$ de MS, também foram verificadas nos fenos de soja perene e kudzu tropical.

A lignina se apresentou, em menores concentrações, nos fenos com umidade intermédiária, nos quais, observou-se valor médio de $121,70 \mathrm{~g} / \mathrm{kg}$ de MS. Resultados inferiores a esse foram constatados por Coblentz e Hoffman (2009b), em fenos de alfafa, encontrando-se teores entre 51,0 e $81,5 \mathrm{~g} / \mathrm{kg}$ de MS.

De acordo com Sanderson e Wedin (1989), citado por Reis, Moreira e Pedreira (2001), devese destacar que apesar das leguminosas usualmente apresentarem valores de FDN cerca de duas vezes menores que as gramíneas, sua parede celular é menos digestível, devido a sua maior concentração de lignina, uma vez que esta se encontra em maiores proporções nos caules.

Assim como os valores de FDN e FDA e lignina, apesar de não terem sido observadas diferenças estatísticas $(\mathrm{P}<0,05)$ entre o conteúdo de CHT do tratamento com $700 \mathrm{~g}$ de $\mathrm{MS} / \mathrm{kg}$ de $\mathrm{MN}$, em relação aos demais tratamentos, verificou-se redução nas concentrações da fração $\mathrm{C}$ e aumento da fração $B_{2}$ (Tabela 7). As frações $A+B_{1}$ foram maiores nos fenos com menores teores de MS, contribuindo, juntamente com a fração $\mathrm{B}_{2}$, para melhores quantidades de componentes digestíveis presentes nos CHT. 
Tabela 7. Frações de carboidratos (g/kg de CHT) dos fenos de Stylosanthes spp. cv. Campo Grande, confeccionados com diferentes teores de matéria seca no momento do enfardamento.

\begin{tabular}{crrrr}
\hline Tratamentos & \multicolumn{4}{c}{ Frações do CHT } \\
\cline { 2 - 5 }$(\mathrm{g}$ de MS/kg de MN) & CHT & \multicolumn{1}{c}{${\mathrm{A}+\mathrm{B}_{1}}^{\mathrm{C}}$} & \multicolumn{1}{c}{$\mathrm{B}$} \\
\hline 600 & $822,69^{\mathrm{a}}$ & $308,30^{\mathrm{a}}$ & $277,27^{\mathrm{b}}$ & $414,43^{\mathrm{a}}$ \\
700 & $816,22^{\mathrm{ab}}$ & $328,13^{\mathrm{a}}$ & $324,29^{\mathrm{a}}$ & $347,58^{\mathrm{b}}$ \\
800 & $812,48^{\mathrm{b}}$ & $274,15^{\mathrm{b}}$ & $274,31^{\mathrm{b}}$ & $451,54^{\mathrm{a}}$ \\
\hline Média & 817,13 & 303,53 & 291,96 & 404,52 \\
CV $(\%)$ & 0,47 & 4,82 & 5,17 & 5,38 \\
\hline
\end{tabular}

Médias na mesma coluna, seguidas de letras diferentes, diferem entre si pelo teste Tukey $(\mathrm{P}<0,05)$.

Fonte: Elaboração dos autores.

Soares Filho (2011) relatou que após o corte, a planta continua viva, podendo fazer fotossíntese por um período de tempo relativamente longo. Além disso, a planta continua com sua respiração celular até atingir o teor de MS próxima a $700 \mathrm{~g} /$ $\mathrm{kg}$ de $\mathrm{MN}$ ou até que a temperatura alcance níveis de $45^{\circ} \mathrm{C}$, quando as células vegetais morrem. Assim, em decorrência da atividade respiratória durante o tempo de secagem, ocorre diminuição no conteúdo de carboidratos solúveis, resultando em aumento, em termos proporcionais, das concentrações de PB, FDN, FDA e de lignina (REIS; MOREIRA; PEDREIRA, 2001).

Em decorrência dos constituintes dos CHT e dos reduzidos valores de NIDN e NIDA, encontrados nos fenos com maior MS (700 e $800 \mathrm{~g} / \mathrm{kg}$ de MN), observou-se maiores valores de NDT e DIVMS, porém, estatisticamente $(\mathrm{P}<0,05)$, o feno enfardado com $700 \mathrm{~g}$ de $\mathrm{MS} / \mathrm{kg}$ de $\mathrm{MN}$ se sobressaiu aos demais, apresentando valores de NDT e DIVMS na ordem de 528,51 e 646,34 g/kg de MS, respectivamente (Tabela 6). Valores semelhantes foram relatados pela Embrapa (2007), em feno de estilosantes Campo Grande, produzido a partir de plantas cortadas no início do florescimento, os quais apresentaram digestibilidade de 550 a $650 \mathrm{~g} / \mathrm{kg}$ de MS.
Perdas de qualidade na fenação do estilosantes cv Campo Grande

Os valores das alterações na qualidade dos fenos, decorrentes do processo de fenação, bem como os valores das perdas, estão apresentados na Tabela 8 .

Confrontando os dados da composição químicobromatológica da forragem no momento do corte com os dos fenos, enfardados com diferentes teores de umidade, pode-se observar que houve pequenas variações $(\mathrm{P}<0,05)$ nos valores médios das variáveis estudadas, indicando que o processo de fenação ocorreu de modo eficiente.

Com o processo de fenação, verificou-se que não houve aumento $(\mathrm{P}>0,05)$ nas concentrações médias de MM. No entanto, observou-se redução $(\mathrm{P}<0,05)$ nos teores de $\mathrm{PB}$ e EE dos fenos enfardados com $600 \mathrm{~g}$ de $\mathrm{MS} / \mathrm{kg}$ de $\mathrm{MN}$, os quais apresentaram maiores perdas desses compostos, possivelmente pelo maior tempo até a estabilização do feno, devido ao prolongamento do tempo de respiração, tanto da planta, quanto dos microrganismos presentes, bem como, pela formação de complexos entre proteínas e carboidratos. 
Tabela 8. Alterações na composição químico-bromatológica ( $\mathrm{g} / \mathrm{kg}$ de MS) e digestibilidade "in vitro" da matéria seca (DIVMS) do Stylosanthes spp. cv. Campo Grande (ECG) e dos seus fenos enfardados com 600, 700 e $800 \mathrm{~g}$ de MS/ $\mathrm{kg}$ de $\mathrm{MN}$, com suas respectivas perdas no processo da fenação.

\begin{tabular}{|c|c|c|c|c|c|c|c|}
\hline & \multicolumn{4}{|c|}{ Tratamentos } & \multicolumn{3}{|c|}{ Perdas no enfardamento } \\
\hline & ECG & 600 & 700 & 800 & 600 & 700 & 800 \\
\hline MM & $53,62^{\mathrm{a}}$ & $58,08^{\mathrm{a}}$ & $53,03^{\mathrm{a}}$ & $51,18^{\mathrm{a}}$ & $-4,46^{\mathrm{a}}$ & $0,59^{\mathrm{a}}$ & $2,44^{\mathrm{a}}$ \\
\hline PB & $118,84^{\mathrm{a}}$ & $113,28^{b}$ & $119,33^{\mathrm{a}}$ & $124,02^{\mathrm{a}}$ & $5,56^{\mathrm{a}}$ & $-0,49^{\mathrm{b}}$ & $-5,17^{b}$ \\
\hline EE & $13,11^{\mathrm{a}}$ & $5,95^{\mathrm{b}}$ & $11,42^{\mathrm{a}}$ & $12,32^{\mathrm{a}}$ & $7,16^{\mathrm{a}}$ & $1,69^{\mathrm{b}}$ & $0,79^{\mathrm{b}}$ \\
\hline FDN & $653,32^{\mathrm{a}}$ & $607,82^{\mathrm{a}}$ & $582,53^{\mathrm{b}}$ & $620,36^{\mathrm{a}}$ & $45,50^{\mathrm{b}}$ & $70,79^{a}$ & $32,96^{\mathrm{b}}$ \\
\hline FDA & $503,16^{\mathrm{a}}$ & $463,25^{\mathrm{ab}}$ & $418,88^{\mathrm{b}}$ & $477,24^{\mathrm{a}}$ & $39,91^{\mathrm{ab}}$ & $84,28^{\mathrm{a}}$ & $25,92^{\mathrm{b}}$ \\
\hline LIG & $160,72^{\mathrm{a}}$ & $149,36^{\mathrm{a}}$ & $121,70^{\mathrm{b}}$ & $155,76^{\mathrm{a}}$ & $11,36^{\mathrm{b}}$ & $39,02^{\mathrm{a}}$ & $4,97^{b}$ \\
\hline NIDN & $7,31^{\mathrm{a}}$ & $6,20^{\mathrm{b}}$ & $5,47^{\mathrm{bc}}$ & $4,90^{\mathrm{c}}$ & $1,10^{\mathrm{b}}$ & $1,84^{\mathrm{ab}}$ & $2,41^{\mathrm{a}}$ \\
\hline NIDA & $2,83^{\mathrm{a}}$ & $2,44^{\mathrm{ab}}$ & $1,65^{\mathrm{c}}$ & $2,20^{\mathrm{b}}$ & $0,39^{\mathrm{b}}$ & $1,17^{\mathrm{a}}$ & $0,63^{\mathrm{b}}$ \\
\hline NDT & $458,95^{\mathrm{b}}$ & $460,74^{b}$ & $528,51^{\mathrm{a}}$ & $476,21^{b}$ & $-1,79^{\mathrm{a}}$ & $-69,56^{b}$ & $-17,26^{\mathrm{a}}$ \\
\hline DIVMS & $526,12^{\mathrm{b}}$ & $581,48^{b}$ & $646,34^{\mathrm{a}}$ & $583,41^{\mathrm{b}}$ & $-55,36^{\mathrm{a}}$ & $-120,22^{b}$ & $-57,29^{a}$ \\
\hline
\end{tabular}

Médias na mesma linha, seguidas de letras diferentes, diferem entre si pelo teste Tukey $(\mathrm{P}<0,05)$. MM = matéria mineral; $\mathrm{PB}=$ proteína bruta; $\mathrm{EE}=$ extrato etéreo; $\mathrm{FDN}=$ fibra em detergente neutro; FDA = fibra em detergente ácido; $\mathrm{LIG}=$ lignina; $\mathrm{NIDN}=$ nitrogênio insolúvel em detergente neutro; NIDA = nitrogênio insolúvel em detergente ácido; NDT = nutrientes digestíveis totais. Fonte: Elaboração dos autores.

Quanto aos teores de FDN, FDA, Lignina, NIDN e NIDA, observou-se que houve redução $(\mathrm{P}<0,05)$ em todos os fenos enfardados com $700 \mathrm{~g}$ de $\mathrm{MS} / \mathrm{kg}$ de MN. Constatou-se ainda, diminuição $(\mathrm{P}<0,05)$ dos valores de FDA e NIDN nos fenos com 600 e $800 \mathrm{~g}$ de $\mathrm{MS} / \mathrm{kg}$ de $\mathrm{MN}$, respectivamente. Estes resultados refletem a melhor qualidade dos fenos enfardados com $700 \mathrm{~g}$ de MS/kg de MN. Fato que se comprova, pela superioridade observada nos teores de NDT e DIVMS destes.

As perdas de nutrientes do feno se iniciam imediatamente após o corte, e algumas alterações bioquímicas, como a respiração e a oxidação são inevitáveis durante a secagem. Desta forma, quanto mais rápida for a remoção de água, menor serão as perdas por esses processos (MUCK; SHINNERS, 2001).

Segundo Reis e Moreira (2011), as perdas no processo de fenação podem ser reduzidas, desde que tomados alguns cuidados, pois quando adequadamente protegido, o feno tende a permanecer com sua qualidade estável durante o armazenamento, ocorrendo pequenas perdas devido a atividade de microrganismos. Porém, quando armazenados em locais desprotegidos e/ou com alto teor de umidade, os fenos podem ter suas perdas aumentadas na ordem de 10 a 15\%, devido às adversidades climáticas. Segundo Cândido et al. (2008), o armazenamento dos fenos em galpões é um método eficiente, porém, mesmo assim podem ocorrer perdas de 50 a $100 \mathrm{~g} / \mathrm{kg}$ de MS nos fenos armazenados com teores de MS abaixo de $800 \mathrm{~g} / \mathrm{kg}$.

Observou-se que durante o armazenamento, as maiores variações de temperatura, nos fardos de feno, ocorreram nos dois primeiros dias, para todos os tratamentos, sendo que a temperatura nos tratamentos de 700 e $800 \mathrm{~g}$ de $\mathrm{MS} / \mathrm{kg}$ de $\mathrm{MN}$ apresentaram menor variação após o segundo dia (Figura 2). Todos os fenos apresentaram temperatura maior que a ambiente, porém, nos fenos enfardados com $600 \mathrm{~g}$ de MS/kg de MN, observou-se maior amplitude, a qual se manteve durante todo o período de avaliação, superior em mais de $10^{\circ} \mathrm{C}$. Verificouse que a elevação da temperatura, nos fenos com $600 \mathrm{~g}$ de $\mathrm{MS} / \mathrm{kg}$ de $\mathrm{MN}$, ocasionou diminuição da qualidade, devido a redução nas concentrações de PB e aumento de NIDN e NIDA (Tabela 8 e Figura 2). Segundo Coblentz e Hoffman (2009b) as concentrações de FDN, FDA, hemicelulose, celulose e lignina aumentam com a elevação da temperatura $\left(<30^{\circ} \mathrm{C}\right)$ no interior dos fardos. 
Figura 2. Temperatura média no interior dos fenos de Stylosanthes spp. cv. Campo Grande enfardados com diferentes tores de MS e temperatura no galpão de armazenamento.

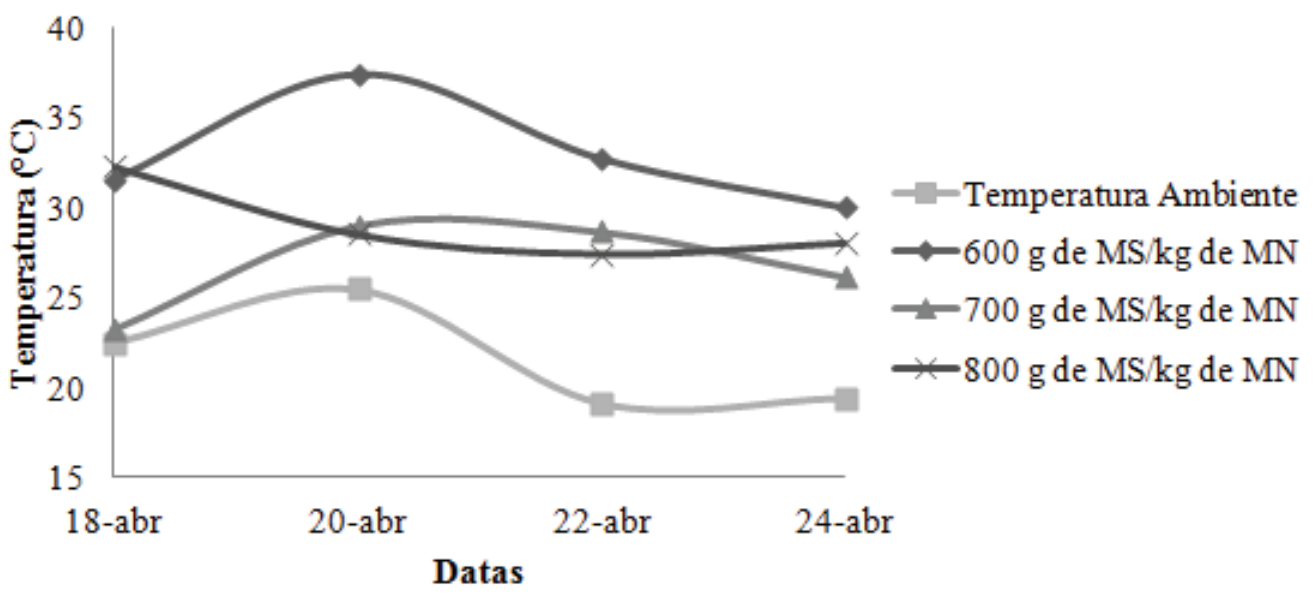

Fonte: Elaboração dos autores.

Durante o armazenamento, se a forragem for enfardada com alto teor de umidade, acima de $200 \mathrm{~g} / \mathrm{kg}$ de $\mathrm{MN}$, podem ocorrer atividades microbiológicas, ocasionando elevação de temperatura nos fardos. Altas temperaturas, acima de $55{ }^{\circ} \mathrm{C}$, nos fardos de feno induz à reações de Maillard e, consequentemente, ocasiona perdas de carboidratos e redução na digestibilidade da proteína. Os produtos dessas reações geralmente provocam o escurecimento e odor desagradável no feno, reduzindo o consumo pelos animais (VAN SOEST, 1994; REIS; MOREIRA; PEDREIRA, 2001). Porém, Silva et al. (2009) avaliando o consumo de feno de ECG, por potros desmamados, observaram que não houve diferença $(\mathrm{P}>0,05)$, entre o consumo do feno de ECG e o de alfafa.

Observou-se uma melhor qualidade, para os fenos com 700 e $800 \mathrm{~g}$ de $\mathrm{MS} / \mathrm{kg}$ de MN, quando comparados a composição da planta inteira de estilosantes, visto que não houve variações nas concentrações de $\mathrm{PB}(\mathrm{P}>0,05)$, no entanto, verificou-se redução $(\mathrm{P}<0,05)$ dos teores de $\mathrm{FDN}$, FDA, NIDN, NIDA e lignina, nos fenos com 700 $\mathrm{g}$ de $\mathrm{MS} / \mathrm{kg}$ de $\mathrm{MN}$ e de NIDN e NIDA nos fenos com $800 \mathrm{~g}$ de MS/kg de MN (Tabela 8). Além disso, verificou-se redução $(\mathrm{P}<0,05)$ da fração $\mathrm{C}$ nos $\mathrm{CHT}$, dos fenos em relação a planta inteira, de 36,01 e $102,86 \mathrm{~g} / \mathrm{kg}$ de MS para fenos enfardados com 600 e $700 \mathrm{~g}$ de $\mathrm{MS} / \mathrm{kg}$ de $\mathrm{MN}$, respectivamente. Associado a estas reduções, observou-se aumento $(\mathrm{P}<0,05)$ nas concentrações das frações $\mathrm{A}+\mathrm{B}_{1}$ nos fenos enfardados com 600, $700 \mathrm{~g}$ de $\mathrm{MS} / \mathrm{kg}$ de $\mathrm{MN}$, em relação a planta inteira, na ordem de 53,59 e 73,78 g/kg de MS, respectivamente, o que ocasionou aumento $(\mathrm{P}<0,05)$ no NDT e na DIVMS, dos fenos com $700 \mathrm{~g}$ de MS/kg de MN, de 458,95 para $528,51 \mathrm{~g} / \mathrm{kg}$ de MS e de 526,12 para $646,34 \mathrm{~g} /$ $\mathrm{kg}$ de MS, respectivamente.

De acordo com Moser (1995), citado por Reis, Moreira e Pedreira (2001), fenos enfardados com alta umidade tem a digestibilidade da MS e de outros nutrientes diminuídas com o armazenamento, uma vez que muitos compostos facilmente digestíveis são perdidos devido à respiração celular. Este fato é verdadeiro, quando analisados sob o ponto de vista do efeito do teor de MS, no momento do enfardamento, sobre a qualidade dos fenos (Tabela 6), porém, se avaliados com relação a composição da planta fenada, os fenos, independentes do teor de MS no momento do enfardamento, apresentaram 
melhores resultados em alguns aspectos (Tabela 8). Contudo, os melhores valores nutricionais foram encontrados nos fenos enfardados com $700 \mathrm{~g}$ de $\mathrm{MS} / \mathrm{kg}$ de $\mathrm{MN}$, possivelmente devido a tendência a diminuição da temperatura dos fardos após o quarto dia de medição (Figura 2), fato que se deu de forma inversa nos fenos com $800 \mathrm{~g}$ de $\mathrm{MS} / \mathrm{kg}$ de $\mathrm{MN}$.

\section{Conclusões}

O feno de ECG demonstrou boas características de composição químico-bromatológica. As menores perdas, assim como a melhor composição, foram apresentadas pelos fenos enfardados com teores de MS iguais a $700 \mathrm{~g} / \mathrm{kg}$ de $\mathrm{MN}$, os quais apresentaram valores superiores de NDT (528,51 g/kg de MS) e DIVMS (646,34 g/kg de MS). Assim, o ECG pode ser utilizado para o preparo de feno, devendo-se adotar um teor de MS médio de $700 \mathrm{~g} / \mathrm{kg}$ de MN no momento do enfardamento, a fim de reduzir as perdas nos processos da fenação e manter a boa qualidade.

\section{Referências}

ALBRECHT, K. A.; BEAUCHEMIN, K. A. Alfalfa and other perennial legume silage. In: BUXTON, D. R.; MUCK, R. E.; HARRISON, J. H. (Ed.). Silage science and technology. Madison: American Society of Agronomy, 2003. p. 633-664.

BARCELLOS, A. O.; ANDRADE, R. P.; KARIA, C. T.; VILELA, L. Potencial e uso de leguminosas forrageiras dos gêneros Stylosanthes, Arachis e Leucaena. In: SIMPÓSIO SOBRE MANEJO DE PASTAGEM, 2. 2000, Piracicaba. Anais... Piracicaba: Fealq, 2000. p. 297.

BERNARDES, T. F.; REIS, R. A. Quando utilizar $o$ ancinho durante o processo de fenação? 2004. Disponível em: <http://www.beefpoint.com.br/radarestecnicos/conservacao-de-forragens/quando-utilizar-oancinho-durante-o-processo-de -fenacao-19970n.aspx>. Acesso em: 05 jan. 2012.

CÂNDIDO, M. J. D.; CUTRIM JÚNIOR, A. J. A.; SILVA, R. G.; AQUINO, R. M. S. Técnicas de fenação para a produção de leite. In: SEMINÁRIO NORDESTINO DE PECUÁRIA- PECNORDESTE, 2008, Fortaleza. Anais... Fortaleza: Faec, 2008. p. 261-298.
COBLENTZ, W. K.; HOFFMAN, P. C. Effects of bale moisture and bale diameter on spontaneous heating, dry matter recovery, in vitro true digestibility, and in situ disappearance kinetics of alfalfa-orchardgrass hays. Journal of Dairy Science, Champaign, v. 92, n. 6, p. 2853-2874, 2009a.

COBLENTZ, W. K.; HOFFMAN, P. C. Effects of spontaneous heating on fiber composition, fiber digestibility, and in situ disappearance kinetics of neutral detergent fiber for alfalfa-orchardgrass hays. Journal of Dairy Science, Champaign, v. 92, n. 6, p. 2875-2895, 2009b.

COBLENTZ, W. K.; HOFFMAN, P. C.; MARTIN, N. P. Effects of spontaneous heating on forage protein fractions and in situ disappearance kinetics of crude protein for alfalfa-orchardgrass hays packaged in large round bales. Journal of Dairy Science, Champaign, v. 93, n. 3, p. 1148-1169, 2010.

EMPRESA BRASILEIRA DE PESQUISA AGROPECUÁRIA - EMBRAPA. Cultivo e uso de estilosantes campo grande. Campo Grande, MS: Embrapa Gado de Corte, 2007. 11 p. (Comunicado técnico, 105).

EVANGELISTA, A. R.; REIS, R. A.; MORAIS, G. Fatores limitantes para a adoção da tecnologia de fenação em diferentes sistemas de produção animal. In: SIMPÓSIO SOBRE PRODUÇÃO E UTILIZAÇÃO DE FORRAGENS CONSEVADAS, 4., 2011, Maringá. Anais... Maringá: UEM/CCA/DZO, 2011. p. 271.

FREITAS, D.; COAN, R. M.; REIS, R. A.; PEREIRA, J. R. A.; PANIZZI, R. C. Avaliação de fontes de amônia para a conservação do feno de alfafa (Medicago sativa L.) armazenado com alta umidade. Revista Brasileira de Zootecnia, Viçosa, v. 31, n. 2, p. 866-874, 2002.

GIBSON, D. J. Grasses and grassland ecology. UK: Oxford University Press, 2009. 305 p.

GOMES, M. F.; PADILHA, J.; COSTA, J. L. F.; PAOKI, A.; NAKASHIMA, P. Análise bidimensional da cobertura pedológica: o caso da fazenda experimental de iguatemi, Maringá-PR. 2011. Disponível em: $<$ http:// www.dge.uem.br/semana/eixo6/trabalho_10.pdf>. Acesso em: 16 jan. 2011.

HOLDEN, L. A. Comparison of methods of in vitro dry matter digestibility for ten feeds. Journal of Dairy Science, Champaign, v. 82, n. 8, p. 1791-1794, 1999.

INSTITUTO AGRONÔMICO DO PARANÁ - IAPAR. Cartas climáticas do Paraná: classificação climática. 2011. Disponível em: <http://www.iapar.br/ modules/ conteudo/conteudo.php? conteudo $=863>$. Acesso em: 13 jan. 2011. 
MALAFAIA, P. A. M.; VALADARES FILHO, S. C.; VIEIRA, R. A. M.; SILVA, J. F. C.; PEREIRA, J. C. Determinação das frações que constituem os carboidratos totais e da cinética ruminal da fibra em detergente neutro de alguns alimentos para ruminantes. Revista Brasileira de Zootecnia, Viçosa, v. 27, n. 4, p. 790-796, 1998.

MERTENS, D. R. Analysis of fiber in feeds its uses feeds evaluation and ration formulation. In: SMPÓSIO INTERNACIONAL DE RUMINANTES, 1992, Lavras. Anais... Lavras: Sociedade Brasileira de Zootecnia, 1992. p. $188-219$.

MOSER, L. E. Post-harvest physiological changes in forage plants. In: MOORE, K. J.; KRAL, D. M.; VINEY, M. K. (Ed.). Post-harvest physiology and preservation of forages. Madison: American Society of Agronomy, 1995. p. 1-19.

MOURA, R. L.; NASCIMENTO, M. P. S. C. B.; RODRIGUES, M. M.; OLIVEIRA, M. E.; LOPES, J. B. Razão folha/haste e composição bromatológica da rebrota de estilosantes Campo Grande em cinco idades de corte. Acta Scientiarum - Animal Sciences, Maringá, v. 33, n. 3, p. 249-254, 2011.

MUCK, R. E.; SHINNERS, K. J. Conserved forage (silage and hay): progress and priorities. In: INTERNATIONAL GRASSLAND CONGRESS, 19., 2001, São Pedro. Proceedings... Piracicaba: Brazilian Society of Animal Husbandry, 2001. p. 633-664.

NATIONAL RESEARCH COUNCIL - NRC. Nutrient requeriments of dairy cattle. 7. ed. Washington, D.C.: National Academy Press, 2001. 381 p.

Nutrient requirements of horse. 6. ed. Washington, D.C.: National Academy Press, 2007. 360 p.

NUSSIO, L. G.; MANZANO, R. P.; PEDREIRA, C. G. S. Valor alimentício em plantas do gênero Cynodon. In: SIMPÓSIO SOBRE MANEJO DE PASTAGEM. MANEJO DE PASTAGENS DE TÍFTON, COASTCROSS E ESTRELA, 15., 1998, Piracicaba. Anais... Piracicaba: Fealq, 1998. p. 203-242.

OLIVEIRA NETO, A. M.; CUNHA FILHO, O. G.; SALUSTIANO, L. V.; FERREIRA, A. C. D. Produção de matéria seca e teores de matéria seca total, proteína bruta e fibra em detergente neutro das leguminosas Cunhã (Clitoria ternatea L.) e estilosantes (Stylosanthes guianensis) cortadas em diferentes idades. In: ZOOTEC, 2009, Águas de Lindóia. Anais... Águas de Lindóia: FZEA/USP, 2009. CD-ROM.
PADUA, F. T.; ALMEIDA, J. C. C.; SILVA, T. O.; ROCHA, N. S.; NEPOMUCENO, D. D. Produção de matéria seca e composição químico-bromatológica do feno de três leguminosas forrageiras tropicais em dois sistemas de cultivo. Ciência Rural, Santa Maria, v. 36, n. 4, p. 1253-1257, 2006.

REIS, R. A.; MOREIRA, A. L. Conservação de forragem como estratégia para otimizar o manejo das pastagens. 2011. Disponível em: <http://ww2.fcav.unesp.br/ ricardoreis/lib/exe/fetch.php.> Acesso em: 20 jun. 2011.

REIS, R. A.; MOREIRA, A. L.; PEDREIRA, M. S. Técnicas para produção e conservação de fenos de forrageiras de alta qualidade. In: SIMPÓSIO SOBRE PRODUÇÃO E UTILIZAÇÃO DE FORRAGENS CONSERVADAS, 1., 2001, Maringá. Anais... Maringá: UEM/CCA/DZO, 2001. p. 1-39.

SANDERSON, M. A.; WEDIN, W. F. Nitrogen concentrations in the cell wall and lignocellulose of smooth bromegrass herbage. Grass and Forage Science, Stephenville, v. 44, n. 2, p. 151-158, 1989.

SAS INSTITUTE. SAS/STAT® user's guide. version 9.2. 2.ed. Cary, North Caroline: Statistical Analysis System Institute Inc, 2009. 7869 p.

SAVOIE, P.; CARON, E.; TREMBLAY, G. F. Control of losses during the haymaking process. In: INTERNATIONAL SYMPOSIUM ON FORAGE QUALITY AND CONSERVATION, 2., 2011, São Pedro. Proceedings... Piracicaba: Fealq, 2011. p. 143-164.

SILVA, D. J.; QUEIROZ, A. C. Análise de alimentos: métodos químicos e biológicos. 3. ed. Viçosa: UFV, 2002. $235 \mathrm{p}$.

SILVA, V.P. Avaliação nutricional de fenos de estilosantes $e$ de alfafa em eqüinos. 2010. Tese (Doutorado em Zootecnia) - Universidade Federal de Minas Gerais. Escola de Veterinária, Belo Horizonte.

SILVA, V. P.; PEREIRA, R. V. G.; LIMA, J. T. M.; MOREIRA, D. C. A.; COSTA, M. L. L.; REZENDE, A. S. C. Feno de estilosantes na dieta de potros da raça Mangalarga Marchador. In: REUNIÃO ANUAL DA SOCIEDADE BRASILEIRA DE ZOOTECNIA, 46., 2009, Maringá. Anais... Maringá: Sociedade Brasileira de Zootecnia, 2009. CD-ROM.

SNIFFEN, C. J.; O'CONNOR, J. D.; VAN SOEST, P. J.; FOX, D. G.; RUSSEL, J. B. A net carbohydrate and protein system for evaluating cattle diets II. Carbohydrate and protein availability. Journal of Animal Science, Champaign, v. 70, n. 11, p. 3562-3577, 1992. 
SOARES FILHO, C. V. Produção de silagem e fenação. 2011. Disponível em: <http://www.foa.unesp.br/ pesquisa/centros_e_nucleos/zootecnia/informacoes tecnicas/forragicultura/Produ $\% \mathrm{C} 3 \% \mathrm{~A} 7 \% \mathrm{C} 3 \% \mathrm{~A} 30 \% 20$ de $\% 20$ silagem $\% 20$ e $\% 20$ fena $\%$ C3\%A $7 \%$ C3\%A3o. pdf $>$. Acesso em: 10 jun. 2011.

TAIZ, L.; ZEIGER, E. Fisiologia vegetal. 3. ed. Porto Alegre, Artmed. 2004. 719 p.

TEIXEIRA, V. I.; DUBEUX JÚNIOR, J. C. B.; SANTOS, M. V. F.; LIRA JÚNIOR, M. A.; LIRA, M. A.; SILVA, H. M. S. Aspectos agronômicos e bromatológicos de leguminosas forrageiras no nordeste brasileiro. Archivos de Zootecnia, Córdoba, v. 59, n. 226, p. 245-254, 2010.
TILLEY, J. M. A.; TERRY, R. A. A two-state tehnique for in vitro digestion of forage crops. Journal of the British Grassland Society, Stareton, v. 18, n. 2, p. 104-111, 1963.

VAN SOEST, P. J. Nutritional ecology of the ruminant. 2. ed. Ithaca: Cornell University Press, 1994. 476 p.

VAN SOEST, P. J.; ROBERTSON, J. B.; LEWIS, B. A. Methods for dietary fiber, neutral detergent fiber, and nonstarch polysaccharides in relation to animal nutrition. Journal of Dairy Science, Champaign, v. 74, n. 12, p. 3583-3597, 1991. 
